\title{
Dihydrocelastrol exerts potent antitumor activity in mantle cell lymphoma cells via dual inhibition of mTORC1 and mTORC2
}

\author{
YONGSHENG XIE ${ }^{1 *}$, BO LI $^{2 *}$, WENXUAN BU ${ }^{1 *}$, LU GAO $^{1}$, YONG ZHANG $^{2}$, XIUCAI LAN ${ }^{1}$, JUN HOU $^{1}$, \\ ZHIJIAN XU ${ }^{2}$, SHUAIKANG CHANG ${ }^{1}$, DANDAN YU ${ }^{1}$, BINGQIAN XIE ${ }^{1}$, YINGCONG WANG ${ }^{1}$, \\ HOUCAI WANG ${ }^{1}$, YIWEN ZHANG ${ }^{1}$, XIAOSONG WU ${ }^{1}$, WEILIANG ZHU ${ }^{2}$ and JUMEI SHI ${ }^{1,3}$ \\ ${ }^{1}$ Department of Hematology, Shanghai Tenth People's Hospital, Tongji University School of Medicine, \\ Shanghai 200072; ${ }^{2}$ CAS Key Laboratory of Receptor Research, Drug Discovery and Design Center, \\ Shanghai Institute of Materia Medica, Chinese Academy of Sciences, Shanghai 201203; ${ }^{3}$ Department of \\ Hematology, Tongji University Cancer Center, Tongji University, Shanghai 200092, P.R. China
}

Received January 24, 2018; Accepted May 16, 2018

DOI: 10.3892/ijo.2018.4438

\begin{abstract}
Mantle cell lymphoma (MCL) is a distinct and highly aggressive subtype of B-cell non-Hodgkin lymphoma. Dihydrocelastrol (DHCE) is a dihydro-analog of celastrol, which is isolated from the traditional Chinese medicinal plant Tripterygium wilfordii. The present study aimed to investigate the effects of DHCE treatment on MCL cells, and to determine the mechanism underlying its potent antitumor activity in vitro and in vivo using the Cell Counting kit- 8 assay, clonogenic assay, apoptosis assay, cell cycle analysis, immunofluorescence staining, western blotting and tumor xenograft models. The results demonstrated that DHCE treatment exerted minimal cytotoxic effects on normal cells, but markedly suppressed MCL cell proliferation by inducing $\mathrm{G}_{0} / \mathrm{G}_{1}$ phase cell cycle arrest, and inhibited MCL cell viability by stimulating apoptosis via extrinsic and intrinsic pathways. In addition, the results revealed that DHCE suppressed cell growth and proliferation by inhibiting mammalian target of rapamycin complex (mTORC)1-mediated phosphorylation of ribosomal protein S6 kinase and eukaryotic initiation factor $4 \mathrm{E}$ binding protein. Simultaneously, DHCE induced apoptosis and inhibited cell survival by suppressing mTORC2-mediated phosphorylation
\end{abstract}

Correspondence to: Professor Jumei Shi, Department of Hematology, Shanghai Tenth People's Hospital, Tongji University School of Medicine, 301 Yanchang Road, Shanghai 200072, P.R. China

E-mail: shijumei@tongji.edu.cn

Professor Weiliang Zhu, CAS Key Laboratory of Receptor Research, Drug Discovery and Design Center, Shanghai Institute of Materia Medica, Chinese Academy of Sciences, 555 Zuchongzhi Road, Shanghai 201203, P.R. China

E-mail:wlzhu@simm.ac.cn

${ }^{*}$ Contributed equally

Key words: mantle cell lymphoma, dihydrocelastrol, apoptosis, cell cycle, mTORC1, mTORC2 of protein kinase B and nuclear factor- $\kappa \mathrm{B}$ activity. In addition to in vitro findings, DHCE treatment reduced the MCL tumor burden in a xenograft mouse model, without indications of toxicity. Furthermore, combined treatment with DHCE and bortezomib, a proteasome inhibitor, induced a synergistic cytotoxic effect on MCL cells. These findings indicated that DHCE may have the potential to serve as a novel therapeutic agent for the treatment of MCL through dually inhibiting mTORC1 and mTORC2.

\section{Introduction}

Mantle cell lymphoma (MCL) is a highly aggressive subtype of B-cell lymphoma, which accounts for 6-8\% of all non-Hodgkin lymphoma diagnoses (1). The malignant cells are present in the mantle zone of the lymph node (2) and are characterized by the molecular hallmark of translocation $\mathrm{t}(11 ; 14)(\mathrm{q} 13 ; \mathrm{q} 32)$, which is associated with cyclin D1 overexpression $(3,4)$. More than $80 \%$ of patients with MCL are diagnosed at stage III or IV of the disease, which is characterized by lymphadenopathy, hepatosplenomegaly and bone marrow involvement (5). Over the last decade, high-dose cytarabine and autologous stem cell transplantation have been used to treat younger patients, whereas rituximab and bendamustine are used to treat older patients. Furthermore, the proteasome inhibitor bortezomib, the immunomodulator lenalidomide, and the Bruton's tyrosine kinase inhibitor ibrutinib have been approved for use in novel therapeutic regimens (4). Although these therapeutic regimens initially exhibit a high rate of complete response, the majority of patients receiving these treatments experience short remission duration with a continuous relapse pattern, leading to incurable MCL with a median survival period of 4-5 years (6). Therefore, there is an urgent need to explore novel molecular targeting agents for the treatment of MCL.

Mammalian target of rapamycin (mTOR) is a highly conserved $289 \mathrm{kDa}$ serine/threonine kinase (7), which is involved in various signaling pathways, including Ras, phosphoinositide 3-kinase (PI3K)/protein kinase B (Akt), hypoxia-inducible factor-1 and nuclear factor (NF)- $\mathrm{B}$. mTOR serves a critical role in the regulation of cell differentiation, 
proliferation and survival (8), and is associated with tumorigenesis, angiogenesis, tumor growth and metastasis (9-11). In addition, mTOR is aberrantly activated in various malignancies and is an indicator of more aggressive diseases, as well as poorer disease prognosis (10-13). mTOR serves as the catalytic subunit of two distinct protein complexes, known as mTOR complex (mTORC)1 and mTORC2. mTORC1 contains mTOR, Raptor and mTOR-associated protein, LST8 homolog (mLST8), whereas mTORC2 is formed by mTOR, Rictor and mLST8 (14). mTORC1 phosphorylates ribosomal protein S6 kinase (p70S6K) and eukaryotic initiation factor 4E binding protein (4E-BP1), which results in protein, nucleotide and lipid synthesis for cell growth and proliferation. mTORC2 autophosphorylates mTOR on Ser2481, and also phosphorylates Akt on Ser473 to control survival and apoptosis $(15,16)$. Numerous hematological malignancies exhibit elevated or aberrant mTOR activation, and mTORC1 and mTORC2 are activated in primary MCL specimens (17). Therefore, numerous clinical trials aimed at evaluating the potential of single agent mTOR-targeted therapies have been launched. Weekly intravenous injection of the mTOR inhibitor temsirolimus has been reported to result in an overall response rate of 38 and $41 \%$ in two studies of patients with relapsed MCL $(18,19)$. Several other clinical trials have indicated that mTOR inhibition can produce antitumor responses in relapsed lymphoma. However, the use of an mTOR targeting agent as a novel therapeutic regimen requires further exploration, particularly for lymphoid malignancies such as MCL (12-14).

Celastrol is a triterpene purified from Tripterygium wilfordii Hook, which possesses antioxidative, ant-apoptotic, ant-inflammatory, anticarcinogenic and ant-obesity properties $(20,21)$. In previous studies, celastrol has been reported to exert anticancer effects on leukemia (22), breast cancer (23), and head and neck cancer (24), as well as other types of tumor. However, the precise mechanism of action of celastrol in lymphoma, particularly in MCL, has not been fully elucidated.

The present study synthesized dihydrocelastrol (DHCE) as a dihydro-analog of celastrol. DHCE exerted potent antitumor activity in MCL cells, in vitro and in vivo, with minimal cytotoxic effects on normal cells. Furthermore, the molecular mechanisms of DHCE action were investigated, and the results revealed that DHCE was an effective inhibitor of mTORC1 and mTORC2. DHCE suppressed growth and proliferation by inhibiting mTORC1-mediated phosphorylation of p70S6K and 4E-BP1. Simultaneously, DHCE induced apoptosis and inhibited cell survival by suppressing mTORC2-mediated phosphorylation of Akt and NF- $\mathrm{KB}$ activity. Taken together, these findings suggested that DHCE may have the potential to serve as a novel therapeutic agent for the treatment of MCL.

\section{Materials and methods}

Cells and cell culture. The human MCL cell lines Jeko-1 and Granta519 were purchased from American Type Culture Collection (Manassas, VA, USA). The human MCL cell lines Z138, Mino and Rec-1 were provided by Dr Xue Han of Tianjin Medical University Cancer Hospital (Tianjin, China). Human peripheral blood mononuclear cells (PBMCs) were acquired from three healthy normal donors ( 2 males, 1 female; age, 24 , 24 and 28 years, respectively) using Ficoll-Hypaque density gradient centrifugation at $568 \mathrm{x} \mathrm{g}$ for $30 \mathrm{~min}$ at room temperature. Informed consent was obtained from each healthy donor. The present study was approved by the institutional review board of Shanghai Tenth People's Hospital (Shanghai, China). The cells were cultured in RPMI-1640 medium (Gibco; Thermo Fisher Scientific, Inc., Waltham, MA, USA) supplemented with $10 \%$ fetal bovine serum (FBS; Gibco; Thermo Fisher Scientific, Inc.) and 1\% penicillin-streptomycin (Gibco; Thermo Fisher Scientific, Inc.). All cells were maintained in a humidified atmosphere containing $5 \% \mathrm{CO}_{2}$ at $37^{\circ} \mathrm{C}$.

Reagents and antibodies. DHCE was synthesized from celastrol using the method previously described by Klaic et al (25). DHCE solution (2 $\mathrm{mM})$ was dissolved in dimethyl sulfoxide (DMSO; Sigma-Aldrich; Merck KGaA, Darmstadt, Germany), stored at $-20^{\circ} \mathrm{C}$ and diluted with cell culture medium to obtain various concentrations. Antibodies against caspase-3 (cat. no. 9665, 1:1,000), cleaved caspase-8 (cat. no. 9496, 1:1,000), caspase-9 (cat. no. 9508, 1:1,000), B-cell lymphoma 2 (Bcl-2)-associated X protein (Bax) (cat. no. 2772, 1:1,000), Bcl-2 (cat. no. 2872, 1:1,000), Bcl-extra large (Bcl-xL) (cat. no. 2764, 1:1,000), Akt (cat. no. 2920, 1:2,000), phosphorylated (p)-Akt (cat. no. 4060, 1:2,000), p-p70S6K (cat. no. 9205, 1:1,000), p70S6K (cat. no. 2708, 1:1,000), p-4E-BP1 (cat. no. 9456, 1:1,000), 4E-BP1 (cat. no. 9644, 1:1,000), p-mTOR (Ser2481) (cat. no. 2974, 1:1,000), mTOR (cat. no. 2983, 1:1,000) and $\beta$-actin (cat. no. 3700, 1:1,000) were purchased from Cell Signaling Technology, Inc. (Danvers, MA, USA). Cyclin D1 (cat. no. ab134175, 1:1,000), cyclin-dependent kinase 4 (CDK4) (cat. no. ab108357, 1:1,000), CDK6 (cat. no. ab124821, 1:1,000), NF- $\kappa \mathrm{B}$ inhibitor $\alpha(\mathrm{I} \kappa \mathrm{B} \alpha)$ (cat. no. ab32518, 1:1,000), p-IкB $\alpha$ (cat. no. ab92700, 1:1,000),

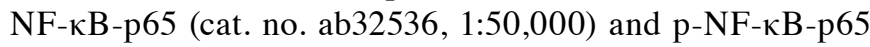
(cat. no. ab76302, 1:10,000) were obtained from Abcam (Cambridge, UK). The pan-caspase inhibitor Z-VAD-FMK was purchased from Selleck Chemicals (Houston, TX, USA). Cell Counting kit-8 (CCK-8) was obtained from Shanghai Yeasen Biotechnology Co., Ltd. (Shanghai, China) and the BD Pharmingen ${ }^{\mathrm{TM}}$ Annexin V/propidium iodide (PI) Apoptosis Detection kit was obtained from BD Biosciences (Franklin Lakes, NJ, USA).

Cell viability assay. Jeko-1, Z138, Mino, Rec-1 and Granta519 cells were plated into $96-$-well plates at a density of $2 \times 10^{5}$ cells $/ \mathrm{ml}$ and were treated with $0.2,0.4,0.6,0.8$ and $1.2 \mu \mathrm{M}$ DHCE for 24,48 and $72 \mathrm{~h}$. PBMCs were plated into 96-well plates at a density of $3 \times 10^{5}$ cells $/ \mathrm{ml}$ and were treated with $1.6 \mu \mathrm{M}$ DHCE for $48 \mathrm{~h}$. After incubation at $37^{\circ} \mathrm{C}$ and $5 \% \mathrm{CO}_{2}, 10 \mu \mathrm{l} \mathrm{CCK}-8$ solution was added to each well and the cells were incubated for an additional $2 \mathrm{~h}$ at $37^{\circ} \mathrm{C}$. Absorbance was then measured at $450 \mathrm{~nm}$ using a microplate reader.

Cell apoptosis detection. Double-staining with the BD Pharmingen ${ }^{\mathrm{TM}}$ Annexin V/PI Apoptosis Detection kit was used to detect cell apoptosis. Following DHCE (0.4, 0.6 and $0.8 \mu \mathrm{M})$ and/or Z-VAD-FMK $(50 \mu \mathrm{M})$ exposure for $48 \mathrm{~h}, 1 \times 10^{5}$ Jeko-1 and Z138 cells were resuspended in $95 \mu \mathrm{l}$ binding buffer and $5 \mu \mathrm{l}$ fluorescein isothiocyanate-conjugated Annexin $\mathrm{V}$ after centrifugation at $142 \mathrm{xg}$ and $4^{\circ} \mathrm{C}$ for $5 \mathrm{~min}$. 
After incubation for $30 \mathrm{~min}$ at $4^{\circ} \mathrm{C}$ in the dark, $500 \mu \mathrm{l}$ binding buffer and $20 \mu \mathrm{l}$ PI solution were added to each cell suspension, and the BD FASCanto II flow cytometer (BD Biosciences) was used for analysis by FlowJo 10 (FlowJo LLC, Ashland, OR, USA). Apoptotic cells were identified as Annexin $\mathrm{V}^{+} / \mathrm{PI}^{-}$(early apoptosis) and Annexin $\mathrm{V}^{+} / \mathrm{PI}^{+}$(late apoptosis).

Cell cycle analysis. Following 0.4 and $0.8 \mu \mathrm{M}$ DHCE exposure for $36 \mathrm{~h}$, Jeko- 1 and Z138 cells at a density of $2 \times 10^{5}$ cells $/ \mathrm{ml}$ were washed with cold PBS, and fixed in $70 \%$ ice-cold ethanol overnight at $-20^{\circ} \mathrm{C}$. The ethanol-fixed samples were washed with PBS, and incubated in $500 \mu \mathrm{l} \mathrm{PI} / \mathrm{RNa}$ se staining buffer (BD Biosciences) for $15 \mathrm{~min}$ at room temperature in the dark prior to flow cytometry. Results were analyzed by ModFit LT 3.2 (Verity Software House, Inc., Topsham, ME, USA).

Clonogenic assay. Jeko-1 and Z138 cells (1x10 4 cells/well) were mixed with RPMI-1640 media containing 10\% FBS and $0.33 \%$ agar, and were layered on top of a base layer of $0.5 \%$ agar in each well of 6-well plates. After culturing for 2 weeks, cells were incubated with $0.5 \%$ crystal violet for $1 \mathrm{~h}$ at room temperature. Subsequently, images of cell colonies were captured using a digital camera after staining with extra crystal violet. The number of cell colonies was semi-quantified using ImageJ 1.51 software (National Institutes of Health, Bethesda, MD, USA).

5-Ethynyl-2'-deoxyuridine (EdU) labeling and immunofluorescence. Jeko- 1 and $\mathrm{Z} 138$ cells were plated into a 6-well plate at a density of $4 \times 10^{5}$ cells/well, and were incubated with or without $0.8 \mu \mathrm{M} \mathrm{DHCE}$ at $37^{\circ} \mathrm{C}$ for $48 \mathrm{~h}$. Subsequently, all cells were incubated with $50 \mu \mathrm{M}$ EdU (Guangzhou RiboBio Co., Ltd., Guangzhou, China) at $37^{\circ} \mathrm{C}$ for $1 \mathrm{~h}$. After being fixed with $4 \%$ paraformaldehyde at room temperature for $30 \mathrm{~min}$, the cells were treated with $0.5 \%$ Triton $\mathrm{X}-100$ at room temperature for $10 \mathrm{~min}$ and washed three times with PBS. Thereafter, the cells were exposed to $100 \mu 11 \mathrm{X}$ Apollo reaction cocktail at $37^{\circ} \mathrm{C}$ for $30 \mathrm{~min}$ and incubated with DAPI at room temperature to stain the cell nuclei for $5 \mathrm{~min}$. A confocal laser-scanning microscope was used to detect stained cells.

DAPI and terminal deoxynucleotidyl-transferase-mediated dUTP nick end labeling (TUNEL) staining. Jeko-1 and Z138 cells were plated into a 6 -well plate at a density of $4 \times 10^{5}$ cells/well, and were incubated with or without $0.8 \mu \mathrm{M}$ $\mathrm{DHCE}$ at $37^{\circ} \mathrm{C}$ for $48 \mathrm{~h}$. After centrifugation at $142 \mathrm{x} \mathrm{g}$ and $37^{\circ} \mathrm{C}$ for $5 \mathrm{~min}$ and washing with PBS, cells were fixed in $4 \%$ paraformaldehyde at $37^{\circ} \mathrm{C}$ for $30 \mathrm{~min}$ and permeabilized with $0.1 \%$ Triton $\mathrm{X}-100$ at $37^{\circ} \mathrm{C}$ for $10 \mathrm{~min}$. After washing, cells were incubated with TUNEL (Beyotime Institute of Biotechnology, Shanghai, China) reaction mixture for $60 \mathrm{~min}$ at $37^{\circ} \mathrm{C}$. Prior to plating on coverslips, cells were stained with DAPI for $5 \mathrm{~min}$ at room temperature in the dark. The cells were imaged under a fluorescence microscope (Zeiss Axiovert 25; Zeiss GmbH, Jena, Germany).

Western blotting. Jeko-1 and Z138 cells were incubated in lysis buffer [100 mM Tris- $\mathrm{HCl}$ (pH 6.8), 4\% SDS, 20\% glycerol] for protein extraction. Protein concentration was determined using the bicinchoninic acid method. Samples containing
$30 \mu \mathrm{g}$ protein were separated by 10 or $12.5 \%$ SDS-PAGE and were then transferred to polyvinylidene difluoride membranes. Membranes were blocked with 5\% non-fat milk or $5 \%$ bovine serum albumin [Anlite (Shanghai) Pharmaceutical Technology Co., Ltd., Shanghai, China] at room temperature for $1 \mathrm{~h}$, and were then incubated overnight at $4^{\circ} \mathrm{C}$ with primary antibodies. Subsequently, the membranes were probed with secondary antibodies [goat ant-mouse immunoglobulin G (IgG), cat. no. 926-32210, 1:1,000; goat ant-rabbit IgG, cat. no. 926-32211, 1:1,000; LI-COR Biosciences, Lincoln, $\mathrm{NE}$, USA) for $60 \mathrm{~min}$ at room temperature, and the blots were detected using the Odyssey two-color infrared laser imaging system (LI-COR Biosciences).

Tumor xenograft model. A total of 8 male nude mice (athymic, BALB/C nu/nu; age, 6 weeks; weight, 17-20 g) were purchased from the Shanghai SLAC Laboratory Animal Co., Ltd. (Shanghai, China). All mice were maintained in an air-conditioned room at $24^{\circ} \mathrm{C}$ with a 12 -hour light/dark cycle and $45 \%$ relative humidity. All mice had free access to water and food. All animal studies were approved by the institutional review board of the Shanghai Tenth People's Hospital (ID: SYXK 2011-0111). Human MCL Jeko-1 cells $\left(10 \times 10^{6}\right)$ were suspended in $100 \mu \mathrm{l}$ serum-free culture medium and were subcutaneously injected into the upper flank region of nude mice. When tumors were measurable, mice were randomly divided into the control and DHCE groups. In the DHCE group, mice were administered $3 \mathrm{mg} / \mathrm{kg}$ DHCE (DHCE was dissolved in 5\% DMSO, $15 \%$ Tween-80 and saline), whereas in the control group, mice received $100 \mu 1$ vehicle (5\% DMSO, 15\% Tween-80 and saline) daily for 19 consecutive days. Tumor size and mouse weight were measured, and the tumor volume was calculated as (length $\mathrm{x}$ width ${ }^{2}$ ) $\mathrm{x} 0.5$. At the end of treatment, mice were sacrificed by cervical dislocation following intraperitoneal injection of $1 \%$ pentobarbital sodium $(50 \mathrm{mg} / \mathrm{kg})$. Hematoxylin-eosin (26) and TUNEL staining of the tumor tissue sections were then performed.

Drug combination study. Jeko-1 and Z138 cells were treated for $24 \mathrm{~h}$ with $\operatorname{DHCE}(0.4,0.6,0.8$ and $1.0 \mu \mathrm{M})$ and/or bortezomib (8, 12, 16 and $20 \mathrm{nM}$ ) (Sigma-Aldrich; Merck KGaA). Combination index $(\mathrm{CI})$ values were calculated using the Chou-Talalay equation (27): CI values $<1$ indicated synergism; CI values equal to 1 indicated an additive effect; and CI values $>1$ indicated antagonism.

Statistical analysis. Data are expressed as the means \pm standard deviation. Statistical analysis was conducted using an unpaired Student's t-test or one-way analysis of variance followed by least significant difference test for multiple comparisons. All statistical analyses were performed using SPSS version 20.0 statistical analysis software (IBM Corp., Armonk, NY, USA). P $\leq 0.05$ was considered to indicate a statistically significant difference.

\section{Results}

DHCE inhibits MCL cell growth and proliferation. As shown in Fig. 1A, DHCE is a synthesized dihydro-analog compound with a molecular weight of 452.6. In the present study, five 
A<smiles>CCC1C2=CCc3c(cc(O)c(O)c3C)C2(C)CCC2(C)CC[C@@](C)(O)C[C@@H]12</smiles>

B

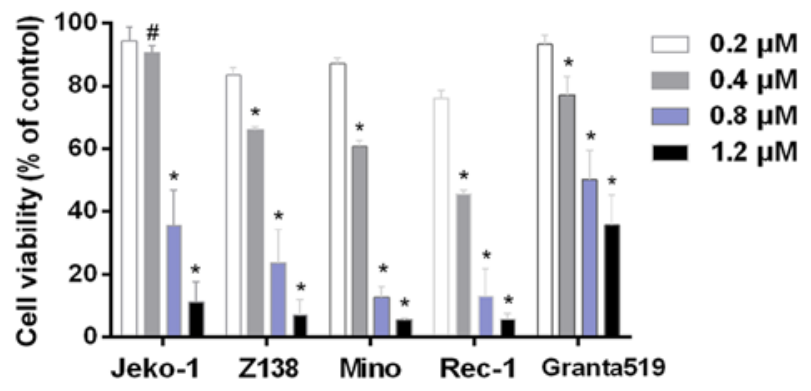

C

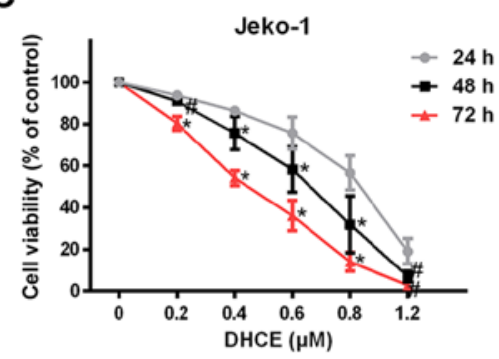

E

$0 \mu \mathrm{M}$

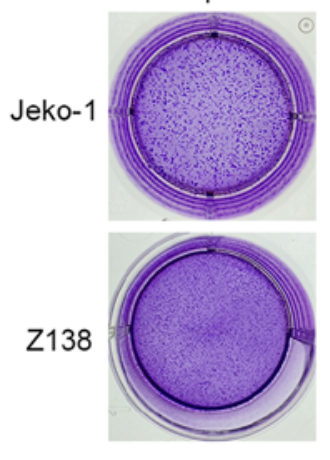

$0.4 \mu \mathrm{M}$

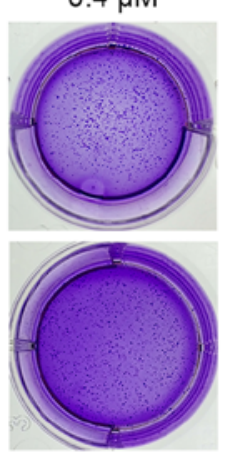

Z138

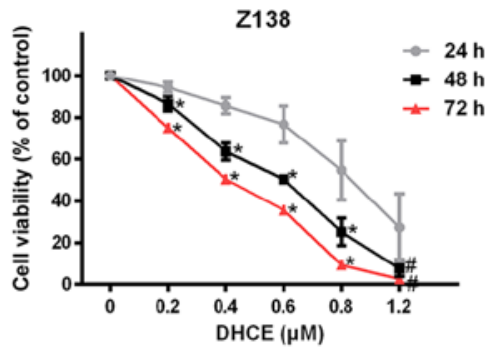

D

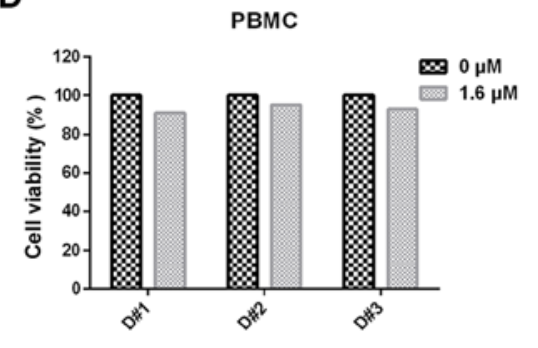

$\mathbf{F}$

$0.8 \mu \mathrm{M}$

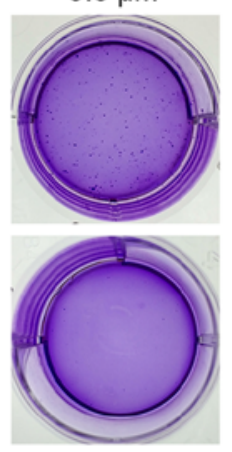

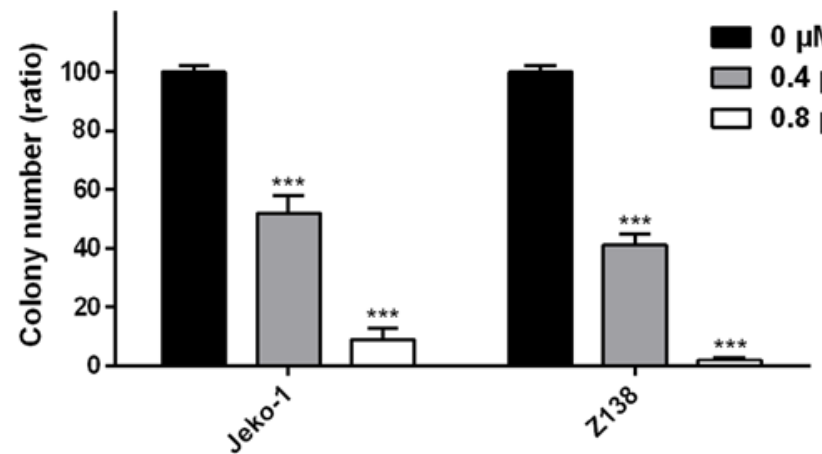
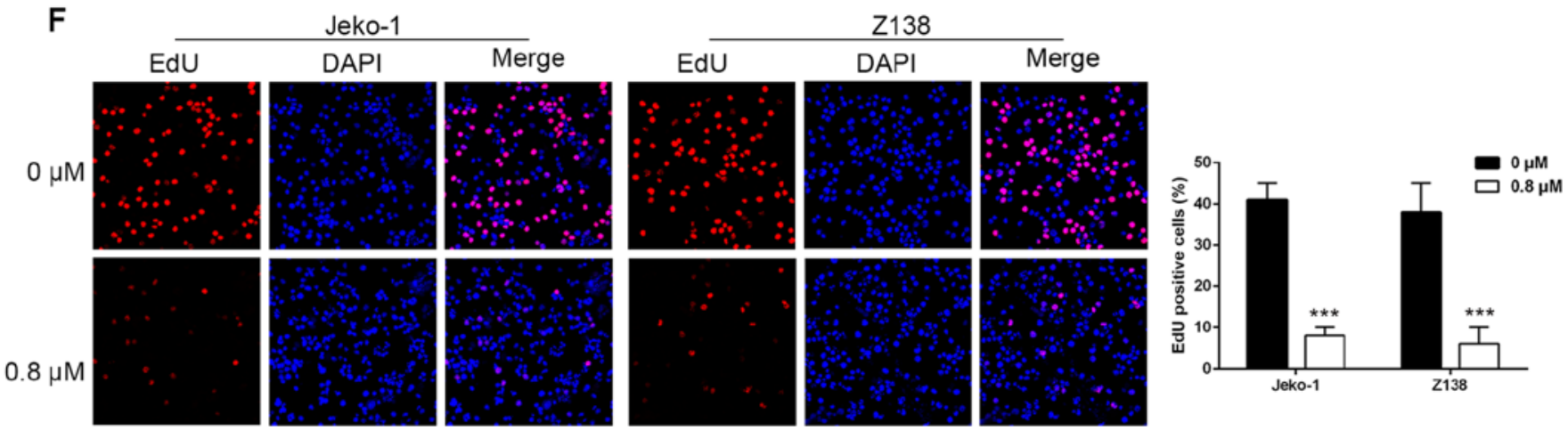

Figure 1. DHCE inhibits proliferation and growth of MCL cells. (A) Chemical structure of DHCE. (B) MCL cell lines were treated with DHCE for 48 h. Cell viability was analyzed using a Cell Counting kit- 8 assay. ${ }^{~} \mathrm{P}>0.05,{ }^{*} \mathrm{P}<0.05$ compared with the $0.2 \mu \mathrm{M}$ group. (C) Jeko-1 and Z138 cells were treated with DHCE $(0.2-1.2 \mu \mathrm{M})$ for 24,48 and $72 \mathrm{~h}$, and viability was then analyzed. ${ }^{*} \mathrm{P}>0.05,{ }^{*} \mathrm{P}<0.05,48 \mathrm{~h}$ group compared with the 72 and $24 \mathrm{~h}$ groups; $72 \mathrm{~h}$ group compared with the 24 and $48 \mathrm{~h}$ groups. (D) PBMCs obtained from three healthy volunteers were treated with DHCE (1.6 $\mu \mathrm{M})$ for $48 \mathrm{~h}$, and cell viability was then measured. (E) Representative images of overall colony formation of Jeko-1 and Z138 cells treated with DHCE. The number of colonies formed in each well was quantified. (F) Representative photomicrographs (original magnification, x50) exhibited decreased proliferation, as determined by EdU immunofluorescence (red), following treatment with $0.8 \mu \mathrm{M}$ DHCE for $48 \mathrm{~h}$. DAPI was used to counterstain nuclei (blue). The number of EdU-positive cells was quantified. Data are presented as the means \pm standard error of the mean $(\mathrm{n}=3) .{ }^{* * * *} \mathrm{P}<0.001$ compared with the $0 \mu \mathrm{M}$ group. DHCE, dihydrocelastrol; EdU, 5-ethynyl-2'-deoxyuridine; MCL, mantle cell lymphoma; PBMCs, peripheral blood mononuclear cells.

MCL cell lines (Jeko-1, Z138, Granta519, Mino and Rec-1) were treated with various doses of DHCE. After $48 \mathrm{~h}$ of DHCE exposure, cell viability was measured using a CCK- 8 assay. MCL cell viability was decreased in a dose-dependent manner (Fig. 1B), and the $48 \mathrm{~h}$ half maximal inhibitory concentration values of DHCE in Jeko-1, Z138, Mino, Rec-1 and Granta519 cells were $0.65 \pm 0.10,0.45 \pm 0.04,0.42 \pm 0.01$, $0.35 \pm 0.03$ and $0.91 \pm 0.08 \mu \mathrm{M}$, respectively. Jeko- 1 and Z138 cells were selected for subsequent analyses, as they have previously been used in numerous studies regarding MCL $(28,29)$. Furthermore, a time-course study of DHCE further demonstrated that cell viability was inhibited in a time-dependent 

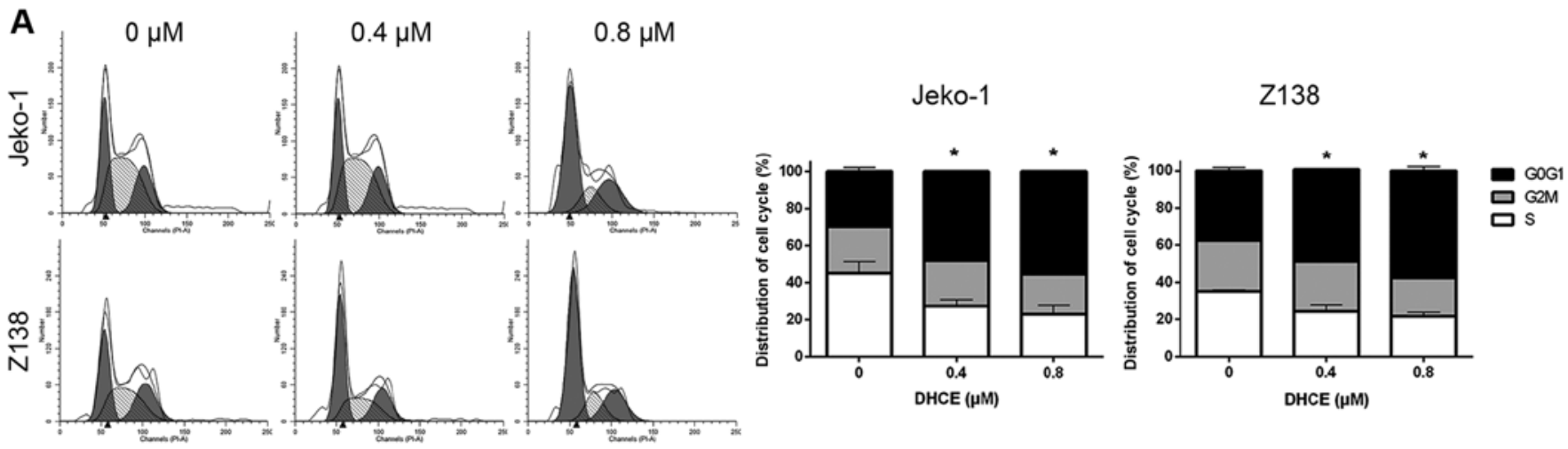

B
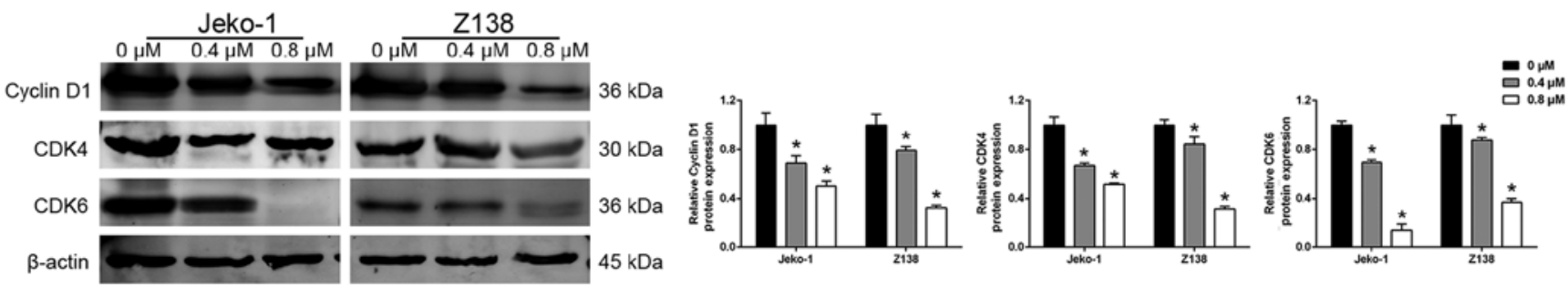

Figure 2. DHCE promotes $\mathrm{G}_{0} / \mathrm{G}_{1}$ arrest in mantle cell lymphoma cells. (A) Jeko-1 and Z138 cells were treated with DHCE $(0,0.4$ and $0.8 \mu \mathrm{M})$ for $36 \mathrm{~h}$. Cells were stained with propidium iodide and analyzed by flow cytometry. Bar graphs show the percentage of cells in the $\mathrm{G}_{0} / \mathrm{G}_{1}, \mathrm{~S}$ and $\mathrm{G}_{2} / \mathrm{M}_{\mathrm{phases}}$ of the cell cycle. ${ }^{*} \mathrm{P}<0.05$ compared with the $0 \mu \mathrm{M}$ group $\left(\mathrm{G}_{0} / \mathrm{G}_{1}\right.$ stage). (B) Protein expression levels of cyclin D1, CDK4, and CDK6 were analyzed by western blot analysis, with $\beta$-actin used as an internal control. Data are expressed as the means \pm standard deviation ( $\mathrm{n}=3)$. ${ }^{*} \mathrm{P}<0.05$ compared with the $0 \mu \mathrm{M}$ group. $\mathrm{CDK}$, cyclindependent kinase; DHCE, dihydrocelastrol.

manner (Fig. 1C). Conversely, at concentrations as high as 1.6 $\mu \mathrm{M}$, DHCE conferred minimal cytotoxic effects on normal PBMCs obtained from three healthy volunteers (Fig. 1D). To investigate the inhibitory effects of DHCE on tumorigenic potential, anchorage-independent colony formation in soft agar was compared between the control and treatment groups. DHCE treatment reduced the ability of Jeko-1 and Z138 cells to form tumorspheres in a dose-dependent manner, and colony formation was almost completely inhibited among Z138 cells treated with $0.8 \mu \mathrm{M}$ DHCE (Fig. 1E). To further explore the effects of DHCE on cell proliferation, the integration of EdU was measured, in order to detect the levels of DNA synthesis; cell nuclei were stained with DAPI. The results demonstrated that DHCE suppressed DNA synthesis in MCL cells, thus indicating that DHCE inhibited proliferation of MCL cells (Fig. 1F). These findings suggested that DHCE may decrease cell viability and inhibit cell proliferation in a dose- and timedependent manner; however, DHCE is not cytotoxic to normal cells.

DHCE promotes cell cycle arrest in MCL cells. The cyclin D1-CDK4 and cyclin D1-CDK6 complexes are critical for the $\mathrm{G}_{1} / \mathrm{S}$ checkpoint, and regulate the progression of cells from $G_{1}$ phase to $S$ phase (30). To evaluate the effects of DHCE on cell cycle progression, Jeko-1 and Z138 cells were treated with DHCE and analyzed by flow cytometry. The results demonstrated that following treatment with DHCE, the percentage of Jeko-1 and Z138 cells in the $\mathrm{G}_{0} / \mathrm{G}_{1}$ phase of the cell cycle was significantly increased (Fig, 2A). The present study also analyzed the expression levels of cell cycle regulatory proteins, and indicated that DHCE suppressed the expression of cyclin D1, CDK4 and CDK6 (Fig. 2B). Taken together, these data suggested that DHCE may induce $\mathrm{G}_{0} / \mathrm{G}_{1}$ phase arrest in a dose-dependent manner by inhibiting the expression of cell cycle regulatory proteins.

DHCE induces apoptosis of MCL cells. Evasion of apoptosis has a key role in tumorigenesis and chemotherapeutic resistance (31). To investigate whether apoptosis is associated with the mechanism underlying the cytotoxic effects of DHCE, Jeko-1 and Z138 cells were incubated with various concentrations of DHCE for $48 \mathrm{~h}$. DHCE markedly increased the percentage of apoptotic cells in a dose-dependent manner, compared with in the control group (Fig. 3A). Furthermore, Jeko-1 and Z138 cells were simultaneously treated with DHCE and a pan-caspase inhibitor, Z-VAD-FMK. The results demonstrated that Z-VAD-FMK induced a significant reduction in DHCE-induced cell apoptosis (Fig. 3B; data of Z138 cells not shown), thus indicating that DHCE-mediated apoptosis is dependent upon caspase activity. These findings demonstrated that DHCE may induce MCL cell apoptosis in a dose-dependent manner.

DHCE induces DNA strand breaks due to apoptosis. A series of morphological alterations are triggered when apoptosis is activated, including cell shrinkage, aberrant chromatin compaction, DNA hydrolysis, nuclear fragmentation and the formation of apoptotic bodies (32). To directly confirm that DHCE promoted the apoptosis of MCL cells, a confocal laser-scanning microscope was used to detect the binding of TUNEL reagent with DNA fragments. Compared with in the control group, MCL cells treated with DHCE for $48 \mathrm{~h}$ exhibited chromatin fragmentation (Fig. 3C), which is a typical morphological characteristic of apoptotic cells. 
A
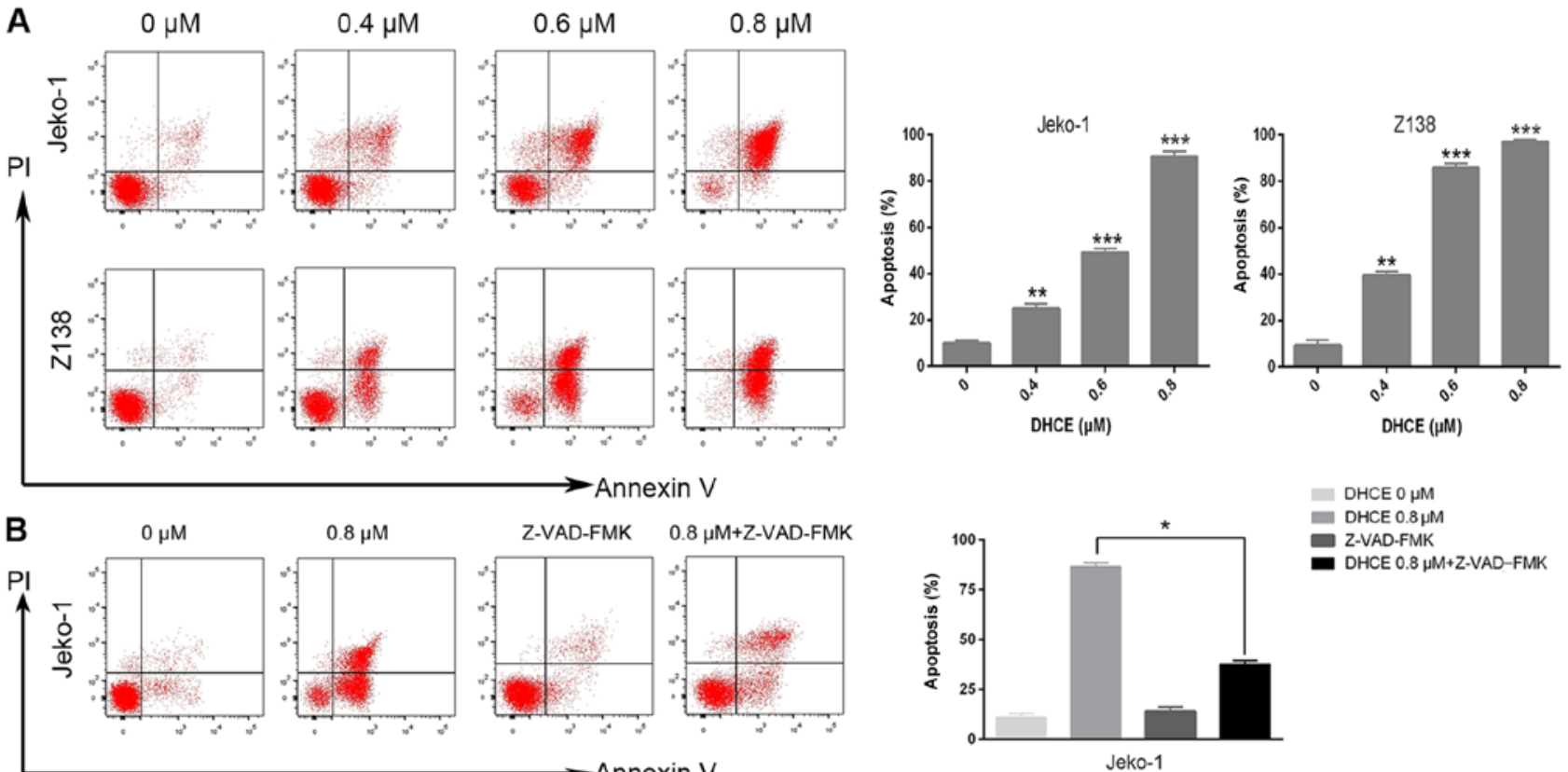

Z-VAD-FMK $\quad 0.8 \mu M+Z-V A D-F M K$
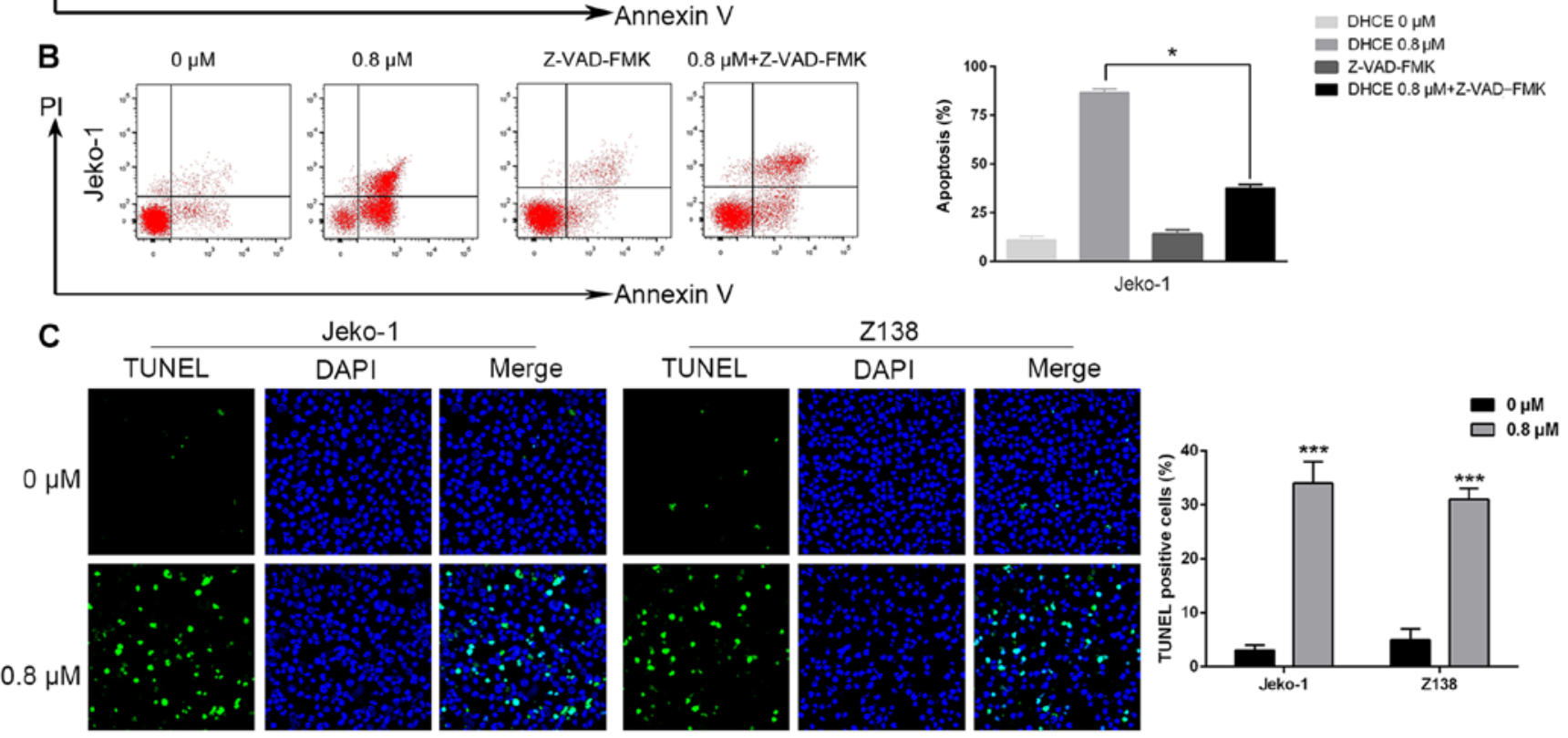

Z-VAD-FMK

Annexin V
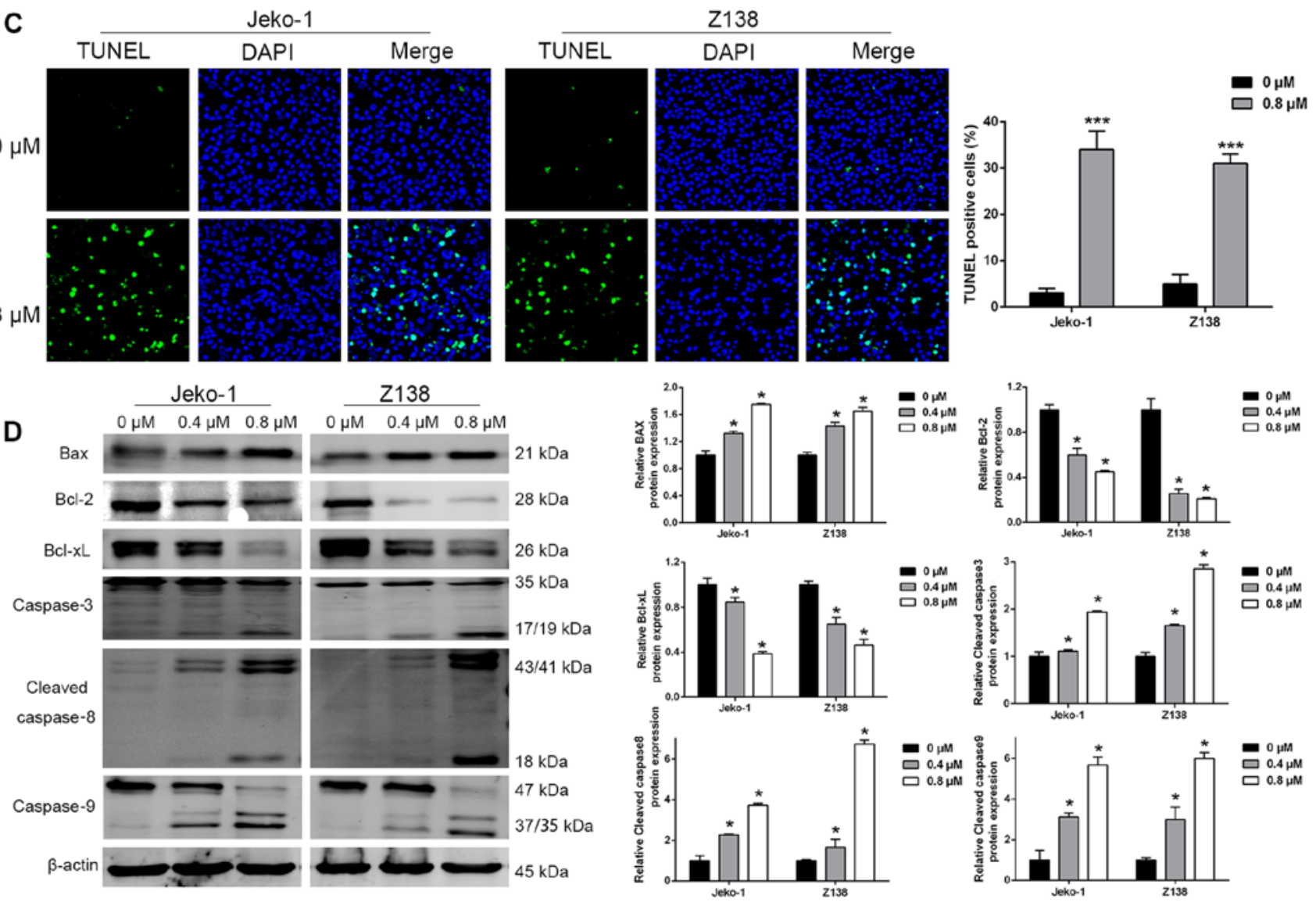

Figure 3. DHCE induces apoptosis of mantle cell lymphoma cells. (A) Cells were treated with DHCE for $48 \mathrm{~h}$ and analyzed by FACS using Annexin V/PI staining. Statistical analysis of apoptosis is presented in the right panel. (B) Cells were incubated with or without the pan-caspase inhibitor Z-VAD-FMK, and were then treated with $0.8 \mu \mathrm{M}$ DHCE for $48 \mathrm{~h}$, stained with Annexin V/PI and analyzed by FACS. Statistical analysis of apoptosis is presented in the right panel. (C) Representative fluorescent images (original magnification, x50) detected increased numbers of apoptotic cells, as evaluated by TUNEL staining (green), following treatment with $0.8 \mu \mathrm{M}$ DHCE for $48 \mathrm{~h}$. DAPI was used as a nuclear stain (blue). The overall number of TUNEL-positive cells was determined and analyzed in the right panel. (D) Expression levels of apoptosis-associated proteins were analyzed using western blot analysis, with $\beta$-actin used as an internal control. Data are expressed as the means \pm standard deviation $(\mathrm{n}=3) .{ }^{*} \mathrm{P}<0.05,{ }^{* *} \mathrm{P}<0.01,{ }^{* * *} \mathrm{P}<0.001$ compared with the $0 \mu \mathrm{M}$ group, or as indicated. Bax, Bcl-2-associated X protein; Bcl-2, B-cell lymphoma 2; Bcl-xL, Bcl-extra large; DHCE, dihydrocelastrol; FACS, fluorescence-activated cell sorting; PI, propidium iodide; TUNEL, terminal deoxynucleotidyl-transferase-mediated dUTP nick end labeling.

These cytological observations further confirmed that DHCE promotes the apoptosis of MCL cells.
DHCE induces caspase-dependent apoptosis through the extrinsic and intrinsic pathways. It is widely known that 

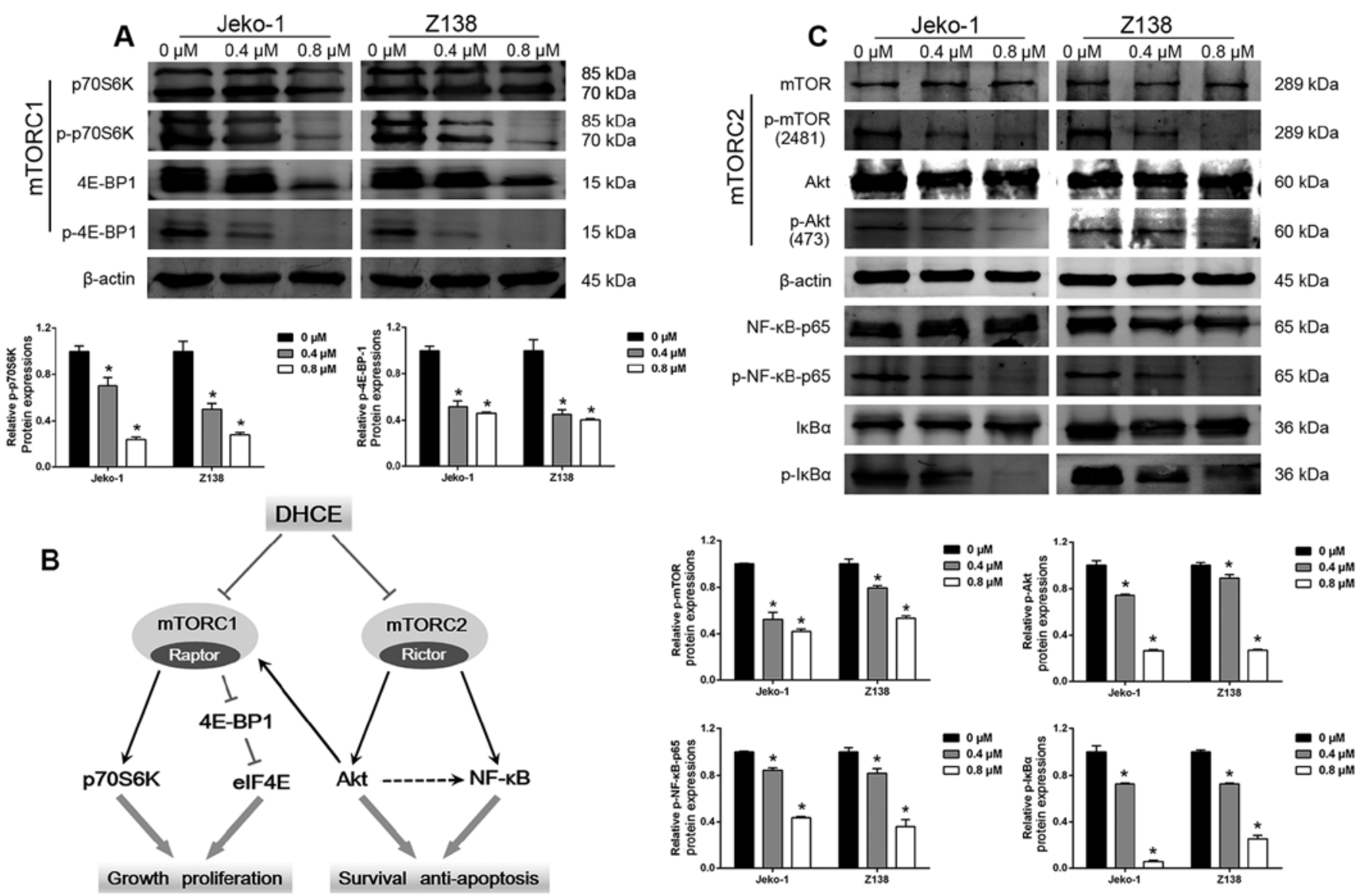

$0.4 \mu \mathrm{M}$ 吕 $0.8 \mu \mathrm{M}$

Figure 4. Mechanisms underlying the antitumor activity of DHCE. (A) DHCE suppressed mTORC1/p70S6K/4E-BP1 signaling. Cells were treated with 0.4 or $0.8 \mu \mathrm{M}$ DHCE for $24 \mathrm{~h}$. Expression levels of mTORC1 kinase activity-related proteins were analyzed using western blot analysis, and phosphorylated protein levels were normalized to the corresponding total protein levels. (B) Diagram illustrating the effects of DHCE on mTORC1 and mTORC2. (C) DHCE suppressed mTORC2/Akt/NF- $\mathrm{B}$ activity. Cells were treated with 0.4 or $0.8 \mu \mathrm{M}$ DHCE for 24 h. Expression levels of mTORC2 kinase activity-related proteins were analyzed using western blot analysis, and phosphorylated protein levels were normalized to the corresponding total protein levels. Data are expressed as the means \pm standard deviation $(\mathrm{n}=3)$. ${ }^{*} \mathrm{P}<0.05$ compared with the $0 \mu \mathrm{M}$ group. $4 \mathrm{E}-\mathrm{BP} 1$, eukaryotic initiation factor $4 \mathrm{E}$ binding protein;

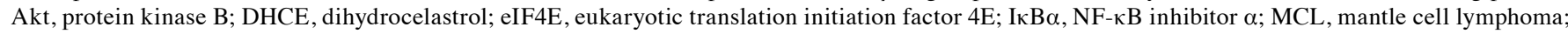

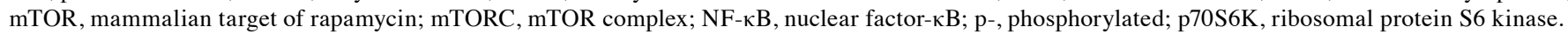

apoptosis signaling pathways consist of extrinsic and intrinsic pathways. Upon receiving specific signals instructing the cells to undergo apoptosis, caspase proteases lead to the cleaving of cellular components including structural proteins in the cytoskeleton and nuclear proteins, such as DNA repair enzymes, through extrinsic and intrinsic pathways (31). DHCE markedly activated caspase- 8 and caspase-3 (Fig. 3D), which are associated with the extrinsic pathway of apoptosis. In addition, DHCE suppressed the expression of the ant-apoptotic proteins Bcl-2 and Bcl-xL, and upregulated the expression of Bax, which is a proapoptotic protein of the intrinsic pathway (Fig. 3D) (33). Increased procaspase-9 substrate cleavage was also detected (Fig. 3D). These findings suggested that DHCE may activate the extrinsic and intrinsic pathways of apoptosis in a dose-dependent manner.

DHCE suppresses mTORC1/p70S6K/4E-BP1. mTORC1 phosphorylates p70S6K and 4E-BP1, which are the two bestcharacterized downstream targets of $\mathrm{mTORC} 1$, thus regulating protein translation and contributing to cell growth and proliferation. To address the potential involvement of mTORC1 in DHCE-mediated inhibition of MCL cell proliferation, the present study measured the protein expression levels of
p70S6K and 4E-BP1. Western blot analysis of Jeko-1 and Z138 cells demonstrated that phosphorylation of p70S6K and 4E-BP1 was inhibited by DHCE in a dose-dependent manner (Fig. 4A). Although DHCE treatment decreased the total protein expression of $4 \mathrm{E}-\mathrm{BP} 1$ after $24 \mathrm{~h}$, phosphorylation of 4E-BP1 was markedly inhibited compared with the control. These results indicated that DHCE-mediated inhibition of cell proliferation and growth may result from the suppression of mTORC1/p70S6K/4E-BP1 activity (Fig. 4B).

DHCE blocks mTORC2/Akt/NF- $\mathrm{m} B$ activity signaling. In contrast to mTORC1, mTORC2 modulates cell survival and apoptosis. Unlike rapamycin, a highly potent and selective inhibitor of mTORC1, which has little or no apoptotic effects on MCL cells (34), DHCE strongly induced apoptosis of Jeko-1 and Z138 cells (Fig. 3). Previous studies demonstrated that Akt regulated the activation of $\mathrm{NF}-\kappa \mathrm{B}$, and that $\mathrm{NF}-\kappa \mathrm{B}$ can be stimulated downstream of mTORC2 by either Akt-dependent or Akt-independent mechanisms (35-38). The present western blot analysis results demonstrated that treatment of $\mathrm{MCL}$ cells with DHCE downregulated the protein expression levels of $\mathrm{NF}-\kappa \mathrm{B}$ target genes, including Bcl-2, Bcl-xL and cyclin D1. Therefore, it was hypothesized that DHCE may 
A

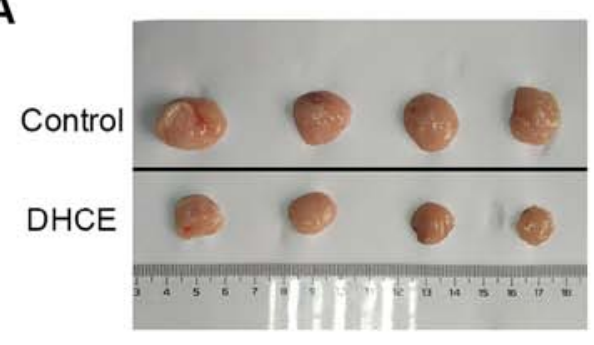

B

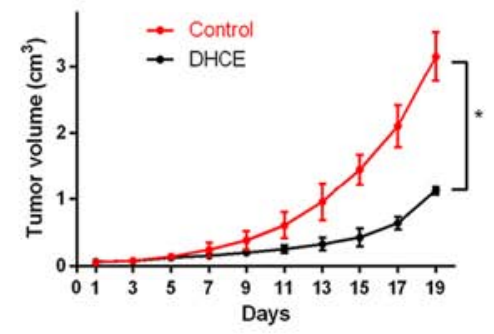

C

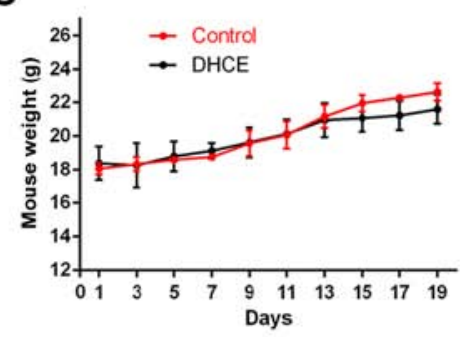

D

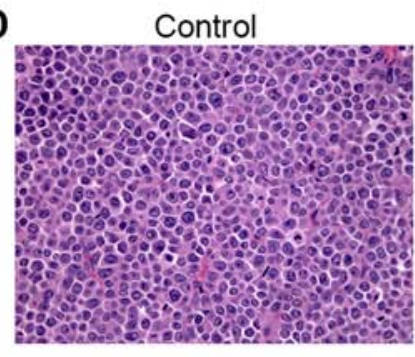

DHCE

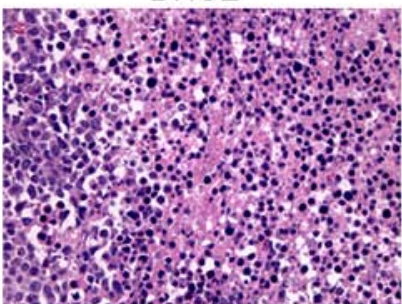

$H \& E$
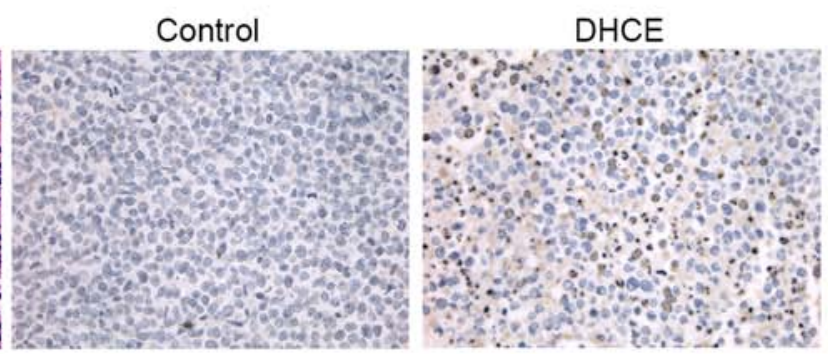

TUNEL

Figure 5. DHCE inhibits mantle cell lymphoma cell xenograft tumor growth. (A) Tumor samples were collected and images were captured using a digital camera. (B) Nude mice bearing subcutaneous Jeko-1 cell xenograft tumors were administered daily intraperitoneal injections of either DHCE (3 mg/kg) or a vehicle control for 19 days. Tumor volume was measured using a caliper. Mean tumor volume $\left(\mathrm{cm}^{3}\right)$ and standard deviation are shown ( $\mathrm{n}=4$ mice/group, $\left.{ }^{*} \mathrm{P}<0.05\right)$. (C) Body weight was measured daily for 19 days. At day 19 the difference between groups was not significant $(\mathrm{P}>0.05)$. Values are expressed as the means \pm standard deviation ( $\mathrm{n}=4$ mice/group). (D) H\&E and TUNEL staining of tumor samples from vehicle- and DHCE-treated mice (original magnification, x400). DHCE, dihydrocelastrol; H7E, hematoxylin and eosin; TUNEL, terminal deoxynucleotidyl-transferase-mediated dUTP nick end labeling.

induce apoptosis of MCL cells by suppressing mTORC2/Akt/ $\mathrm{NF}-\mathrm{kB}$ signaling. Treatment of cells with DHCE resulted in a marked, dose-dependent inhibition of Akt (Ser473) and mTOR (Ser2481) phosphorylation in Jeko-1 and Z138 cells compared with in the control group (Fig. 4C). DHCE treatment exerted only a minimal effect on total mTOR and total Akt protein expression. Subsequently, the effects of DHCE on NF- $\mathrm{kB}$ activity were assessed and demonstrated that DHCE treatment

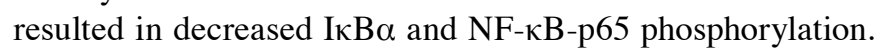
These findings suggested that DHCE may block the activity of mTORC2/Akt/NF- $\mathrm{KB}$, thus leading to apoptosis and inhibition of cell survival (Fig. 4B).

DHCE inhibits tumor growth in a xenograft mouse model. The present study further examined the therapeutic efficacy of DHCE using a xenograft mouse model. Nude mice bearing subcutaneous Jeko-1 cell xenograft tumors were administered daily intraperitoneal injections of either DHCE $(3 \mathrm{mg} / \mathrm{kg})$ or a vehicle control. The diameter and volume of the largest tumor in these mice was $1.98 \mathrm{~cm}$ and $3.20 \mathrm{~cm}^{3}$, respectively. DHCE treatment markedly decreased tumor size (Fig. 5A) and significantly decreased tumor volume (Fig. 5B); however, body weight was not significantly altered between the DHCE-treated and vehicle-treated mice (Fig. 5C). The results of H\&E staining demonstrated that necrosis in the tumor samples of the DHCE-treated group was increased compared with in the vehicle control group. TUNEL staining revealed that DHCE treatment increased apoptosis compared with in the vehicle control group (Fig. 5D). DHCE treatment was well tolerated; no symptoms of poor health or abnormal behaviors were observed in DHCE-treated or vehicle-treated mice, and microscopic examination of individual organs revealed no evidence of tissue damage in either treatment group (data not shown). Consistent with the in vitro observations, these in vivo findings demonstrated that DHCE may inhibit MCL tumor growth in a xenograft model without exerting lethal toxicity.

DHCE acts synergistically with bortezomib in MCL cells. Combination chemotherapy is a rational strategy for the treatment of MCL (4). Combination treatment with DHCE and bortezomib inhibited growth in both cell lines to a greater degree than treatment with DHCE or bortezomib alone. In the present study, CI values were $<1.0$, indicating synergism of DHCE and bortezomib (Fig. 6). Combined treatment of MCL cells with DHCE and bortezomib exhibited clear synergistic effects on the inhibition of cell proliferation.

\section{Discussion}

Despite recent developments resulting in the generation of novel treatment regimens for MCL, the disease remains incurable, with many patients experiencing short periods of remission followed by continuous relapse. Novel drugs are required to further improve the outcome of patients with MCL. Numerous reports have confirmed that the triterpenoid celastrol is an effective antitumor analog in leukemia, breast cancer, gastric cancer, head and neck cancer, and multiple myeloma (22-24). However, little is currently known regarding the use of this compound in lymphoma, and to the best of our knowledge, the present study is the first to directly assess the use of a triterpenoid in MCL. DHCE is a novel triterpene, and the present study explored the effects and relevant mechanisms of DHCE in MCL cells.

Cell cycle dysregulation and evasion of apoptosis, both of which are hallmarks of tumor cells, contribute to tumorigenesis and chemical resistance (39). In general, when confronted with 
A

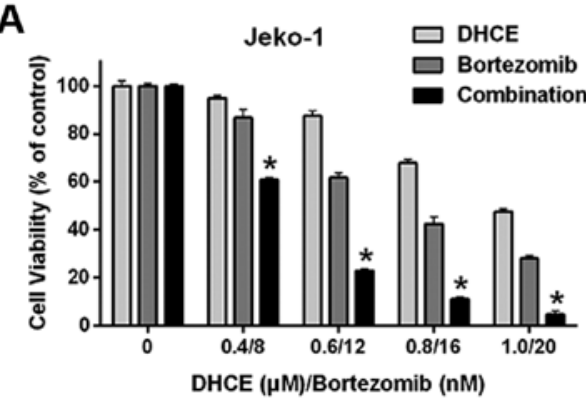

B

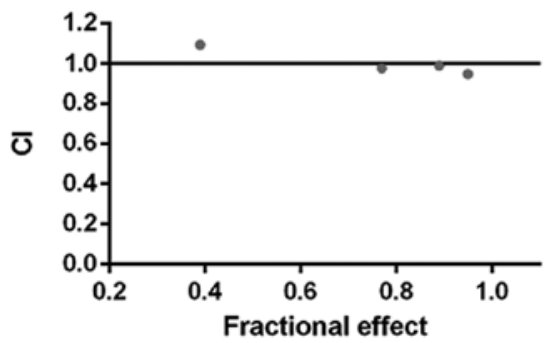

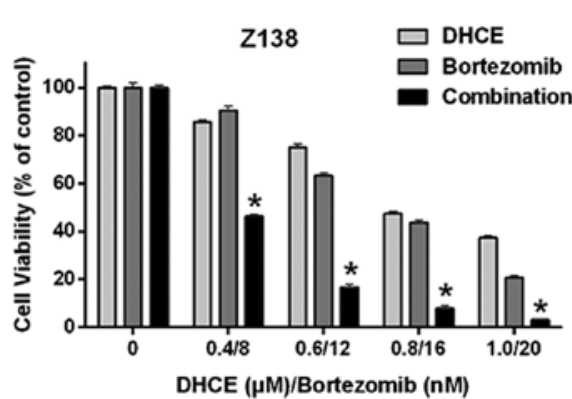

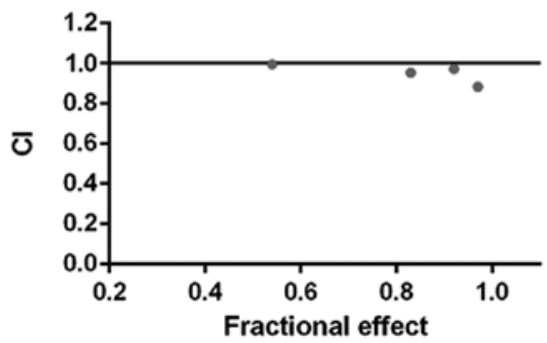

Figure 6. DHCE exhibits a synergistic effect with bortezomib in mantle cell lymphoma cells. (A) Jeko-1 and Z138 cells were treated for 24 h with varying concentrations of DHCE and/or bortezomib. Cell viability was assessed using a Cell Counting kit- 8 assay. ${ }^{*} \mathrm{P}<0.05$ compared with the DHCE and bortezomib groups. (B) CI values were calculated based on the median-effect principle. CI $<1$ indicates synergism of DHCE and bortezomib. The mean values of three experiments are shown. DHCE, dihydrocelastrol; CI, combination index.

stress or damage, cells activate DNA damage checkpoints and initiate DNA repair; however, with persistent cellular impairments, DNA damage cannot be appropriately repaired and the DNA damage checkpoint pathway is activated to eliminate potentially harmful DNA-damaged cells via apoptosis (40). Targeting the apoptosis pathways is a promising opportunity to eradicate cancer (31). Cyclin D1, along with CDK4 and CDK6, regulates $\mathrm{G}_{1} / \mathrm{S}$ progression through phosphorylation of retinoblastoma protein (39). Treatment of MCL cells with DHCE resulted in a downregulation of cyclin D1, CDK4 and CDK6 expression, which then led to $G_{0} / G_{1}$ phase cell cycle arrest. Fluorescence-activated cell sorting analysis and TUNEL/DAPI double staining revealed that DHCE induced apoptosis of MCL cells in a dose-dependent manner, which was suppressed by the pan-caspase inhibitor Z-VAD-FMK. The ability of DHCE to induce apoptosis was associated with the activity of apoptotic proteins. Proteins of the Bcl-2 family are key regulators of the intrinsic apoptotic pathway, including Bcl-2, Bcl-xL and Bax, which ultimately activate caspase-9 at the apoptosome (41). Caspase- 8 is a key initiator caspase that can directly activate caspase-3, thus promoting apoptosis via the extrinsic pathway (31). DHCE treatment resulted in activation of caspase- 3 , caspase- 8 and caspase- 9 . Furthermore, DHCE treatment decreased the expression of the ant-apoptotic mitochondrial proteins $\mathrm{Bcl}-2$ and $\mathrm{Bcl}-\mathrm{xL}$, and increased the expression of the proapoptotic mitochondrial protein Bax. These findings suggested that DHCE treatment may induce the caspase-dependent apoptosis of MCL cells via extrinsic and intrinsic apoptotic pathways.

The mTOR pathway is considered a promising target for cancer therapeutics $(42,43)$. mTORC1 activity affects cell growth and metabolism by phosphorylating p70S6K and 4E-BP1, which regulate protein synthesis, as well as lipid, nucleotide and glucose metabolism. Upon phosphorylation, p70S6K becomes activated, which is critical for lipid and ribosome biogenesis pathways and protein translation. The phosphorylation of 4E-BP1 causes its dissociation from the translation initiation factor eukaryotic translation initiation factor 4E, thus triggering 5'cap-dependent mRNA translation (44). mTORC2 controls apoptosis by autophosphorylating mTOR on Ser2481 with Rictor, and by phosphorylating Akt on Ser473 (7). Rapamycin, which is a well-known mTORC1 inhibitor, and analogs of rapamycin, incompletely inhibit mTORC1 and only inhibit mTORC2 when administered at high doses for a prolonged duration $(34,44)$, due to the presence of a negative feedback loop between mTORC1 and the insulin/PI3K signaling pathway. mTORC1 phosphorylates growth factor receptor bound protein 10 to inhibit insulin/ insulin-like growth factor 1 receptor signaling, which is an upstream activator of Akt and mTORC2. Therefore, inhibition of mTORC1 alone removes the negative feedback on insulin/ PI3K/Akt signaling, allowing Akt to become activated, which ultimately promotes cell survival and prevents apoptosis (45). Other similar feedback mechanisms also exist, which limit the effectiveness of mTORC1 inhibitors. Treatment of established cell lines or primary MCL cultures with rapamycin induces little or no apoptotic response (34). Inhibition of mTORC1 alone has negligible effects on apoptosis in several cell lines; however, suppressing both mTORC1 and mTORC2 presents a more effective strategy. In the present study, it was demonstrated that treatment of MCL cells with DHCE reduced p70S6K and 4E-BP1 phosphorylation, indicating that DHCE suppressed mTORC1 activity. Therefore, it may be concluded that DHCE inhibits the growth and proliferation of MCL cells through suppression of the mTORC1/p70S6K/4E-BP1 pathway.

Although the activity of mTORC1 can be assessed by determining the phosphorylation status of its downstream substrates, a specific downstream marker of mTORC2 activity has not been identified to date. Previous studies have demonstrated 
that knockdown of the mTORC2 protein Rictor, but not the mTORC1 protein Raptor, significantly inhibits activity of Akt as well as that of NF- $\kappa \mathrm{B}(46,47)$, which controls cell survival and apoptosis $(48,49)$. Once phosphorylated by mTORC2, Akt regulates transcriptional activity of NF- $\mathrm{kB}$ by inducing phosphorylation and subsequent degradation of IкB (36), or by phosphorylating $\mathrm{I} \kappa \mathrm{B}$ kinase, which increases the activity of NF- $\mathrm{\kappa B}$ and stimulates the transcription of prosurvival genes (42). In addition, mTORC2 directly promotes NF- $\mathrm{KB}$ activation through the serum/glucocorticoid-regulated kinase 1-dependent pathway or via the phosphorylation of protein kinase C $(35,37,38)$. In the present study, it was demonstrated that phosphorylation of mTOR (Ser2481) and Akt (Ser473) were significantly decreased in MCL cells following treatment with DHCE, thus indicating that DHCE inhibited mTORC2. Consistent with these findings, a reduction in the phosphorylation of I $\mathrm{KB} \alpha$ and NF- $\kappa \mathrm{B}-\mathrm{p} 65$ was observed, thus indicating the reduction of NF- $\kappa \mathrm{B}$ activity. Due to the suppression of NF- $\kappa \mathrm{B}$ activity, the expression levels of NF- $\kappa \mathrm{B}$ targets, including Bcl-2, Bcl-xL and cyclin D1, were also decreased. Therefore, DHCE may exhibit a potent apoptotic effect on MCL cells due to the suppression of mTORC2/Akt/NF- $\kappa \mathrm{B}$ activity. These findings are in agreement with previous studies $(35,37,38)$. However, a recent report indicated that mTORC2 activity suppresses NF- $\kappa \mathrm{B}$ signaling (50). Further studies are required to determine how mTORC1 and mTORC2 regulate NF- $\mathrm{BB}$ activity.

In the present study, DHCE was able to suppress tumor growth in vivo without causing toxicity by inducing the apoptosis of MCL cells. Intraperitoneal administration of $3 \mathrm{mg} / \mathrm{kg}$ DHCE for 19 days resulted in a significant inhibition of tumor growth, with no clear indications of toxicity. Consistent with the in vitro results, immunohistochemical analysis of the tumor samples confirmed that DHCE administration induced apoptosis.

Combined treatment of MCL cells with DHCE and bortezomib, a proteasome inhibitor, enhanced the inhibition of cell proliferation that was achieved with DHCE or bortezomib alone. To further evaluate the synergy between the two drugs, the CI values were calculated; the results demonstrated that values were $<1.0$, thus indicating that DHCE and bortezomib acted synergistically to induce cytotoxicity in MCL cells. Bortezomib is approved for use by the Food and Drug Administration of United States of America and is currently used in MCL treatment regimens. Combination therapies are often used as a strategy to minimize cytotoxicity and resistance (4). The present results indicated that combined therapy with DHCE and bortezomib may be a promising strategy to overcome cytotoxicity and resistance in patients with MCL. However, further validation and exploration is required to fully determine the cooperative mechanism and synergism between these drugs.

In conclusion, DHCE exhibited potent antitumor activity in MCL cell lines and in an MCL xenograft model, at doses that have little effect on normal cells and are well tolerated in mice. The results demonstrated that DHCE suppressed cell growth and proliferation by inhibiting mTORC1-mediated phosphorylation of p70S6K and 4E-BP1. Simultaneously, DHCE induced apoptosis and inhibited cell survival by suppressing mTORC2-mediated phosphorylation of Akt

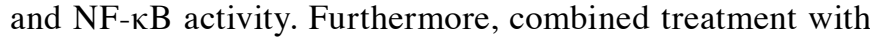
DHCE and bortezomib resulted in synergistic cytotoxic effects on MCL cells. The present study therefore supported the important role of the mTOR pathway in the tumorigenesis of MCL, thus suggesting the necessity of dually inhibiting mTORC1/p70S6K/4E-BP1 and mTORC2/Akt/NF- $\kappa$ B activity in MCL therapy. With further investigation into the associated molecular mechanisms and clinical implications of DHCE administration, DHCE has the potential to serve as a novel therapeutic regimen to improve the outcomes of patients with MCL.

\section{Acknowledgements}

The authors would like to thank Dr. Xue Han of Tianjin Medical University Cancer Hospital (Tianjin, China) for providing the human MCL cell lines.

\section{Funding}

The present study was supported by grants from the National Natural Science Foundation of China (grant nos. 81570190, 81529001, 81670194 and 81602515).

\section{Availability of data and materials}

All data generated or analyzed during this study are included in this published article.

\section{Authors' contributions}

JS, WZ, YX, and BL designed the research; JS, WZ, YX, and $\mathrm{BL}$ organized, analyzed, and interpreted the data; $\mathrm{YX}, \mathrm{BL}$, WB, LG, YoZ, XL, JH, ZX, SC, DY, BX, YW, HW and XW performed the experiments; JS, WZ, YX and BL drafted the manuscript; JH, HW and YiZ contributed to clinical sample collection. All authors read and approved the final manuscript.

\section{Ethics approval and consent to participate}

Informed consent was obtained from each healthy donor. The present study was approved by the institutional review board of Shanghai Tenth People's Hospital (Shanghai, China). All animal studies were approved by the institutional review board of the Shanghai Tenth People's Hospital (ID: SYXK 2011-0111).

\section{Patient consent for publication}

All volunteers consent to the publication.

\section{Competing interests}

The authors declare that they have no competing interests.

\section{References}

1. Spurgeon SE, Till BG, Martin P, Goy AH, Dreyling MP, Gopal AK, LeBlanc M, Leonard JP, Friedberg JW, Baizer L, et al: Recommendations for clinical trial development in mantle cell lymphoma. J Natl Cancer Inst 109: 109, 2016. 
2. Zhou Y, Wang H, Fang W, Romaguer JE, Zhang Y, Delasalle KB, Kwak L, Yi Q, Du XL and Wang M: Incidence trends of mantle cell lymphoma in the United States between 1992 and 2004 Cancer 113: 791-798, 2008

3. Bosch F, Jares P, Campo E, Lopez-Guillermo A, Piris MA Villamor N, Tassies D, Jaffe ES, Montserrat E, Rozman C, et al: PRAD-1/cyclin D1 gene overexpression in chronic lymphoproliferative disorders: A highly specific marker of mantle cell lymphoma. Blood 84: 2726-2732, 1994.

4. Cheah CY, Seymour JF and Wang ML: Mantle cell lymphoma J Clin Oncol 34: 1256-1269, 2016.

5. Hamad N, Armytage T, Mcllroy K, Singh N and Ward C: Primary cutaneous mantle-cell lymphoma: A case report and literature review. J Clin Oncol 33: e104-e108, 2015.

6. Campo E and Rule S: Mantle cell lymphoma: Evolving management strategies. Blood 125: 48-55, 2015.

7. Lee JS, Vo TT and Fruman DA: Targeting mTOR for the treatment of B cell malignancies. Br J Clin Pharmacol 82: 1213-1228, 2016.

8. Strimpakos AS, Karapanagiotou EM, Saif MW and Syrigos KN: The role of mTOR in the management of solid tumors: An overview. Cancer Treat Rev 35: 148-159, 2009.

9. Baldo P, Cecco S, Giacomin E, Lazzarini R, Ros B and Marastoni S: mTOR pathway and mTOR inhibitors as agents for cancer therapy. Curr Cancer Drug Targets 8: 647-665, 2008.

10. Inoki K, Corradetti MN and Guan KL: Dysregulation of the TSC-mTOR pathway in human disease. Nat Genet 37: 19-24, 2005.

11. Lee DF, Kuo HP, Chen CT, Hsu JM, Chou CK, Wei Y, Sun HL, Li LY, Ping B, Huang WC, et al: IKK beta suppression of TSC1 links inflammation and tumor angiogenesis via the mTOR pathway. Cell 130: 440-455, 2007.

12. Eyre TA, Collins GP, Goldstone AH and Cwynarski K: Time now to TORC the TORC? New developments in mTOR pathway inhibition in lymphoid malignancies. Br J Haematol 166: 336-351, 2014.

13. Peponi E, Drakos E, Reyes G, Leventaki V, Rassidakis GZ and Medeiros LJ: Activation of mammalian target of rapamycin signaling promotes cell cycle progression and protects cells from apoptosis in mantle cell lymphoma. Am J Pathol 169: 2171-2180, 2006.

14. Saxton RA and Sabatini DM: mTOR signaling in growth, metabolism, and disease. Cell 168: 960-976, 2017.

15. Dancey J: mTOR signaling and drug development in cancer. Nat Rev Clin Oncol 7: 209-219, 2010.

16. Sarbassov DD, Guertin DA, Ali SM and Sabatini DM Phosphorylation and regulation of Akt/PKB by the rictor-mTOR complex. Science 307: 1098-1101, 2005.

17. Gupta M, Hendrickson AE, Yun SS, Han JJ, Schneider PA, Koh BD, Stenson MJ, Wellik LE, Shing JC, Peterson KL, et al Dual mTORC1/mTORC2 inhibition diminishes Akt activation and induces Puma-dependent apoptosis in lymphoid malignancies. Blood 119: 476-487, 2012.

18. Witzig TE, Geyer SM, Ghobrial I, Inwards DJ, Fonseca R, Kurtin P, Ansell SM, Luyun R, Flynn PJ, Morton RF, et al: Phase II trial of single-agent temsirolimus (CCI-779) for relapsed mantle cell lymphoma. J Clin Oncol 23: 5347-5356, 2005.

19. Ansell SM, Inwards DJ, Rowland KM Jr, Flynn PJ, Morton RF, Moore DF Jr, Kaufmann SH, Ghobrial I, Kurtin PJ, Maurer M, et al: Low-dose, single-agent temsirolimus for relapsed mantle cell lymphoma: A phase 2 trial in the North Central Cancer Treatment Group. Cancer 113: 508-514, 2008.

20. Liu J, Lee J, Salazar Hernandez MA, Mazitschek R and Ozcan U: Treatment of obesity with celastrol. Cell 161: 999-1011, 2015.

21. Kannaiyan R, Shanmugam MK and Sethi G: Molecular targets of celastrol derived from Thunder of God Vine: Potential role in the treatment of inflammatory disorders and cancer. Cancer Lett 303: 9-20, 2011.

22. Sethi G, Ahn KS,Pandey MK and Aggarwal BB: Celastrol, a novel triterpene, potentiates TNF-induced apoptosis and suppresses invasion of tumor cells by inhibiting NF-kappaB-regulated gene products and TAK1-mediated NF-kappaB activation. Blood 109: 2727-2735, 2007.

23. Jang SY, Jang SW and Ko J: Celastrol inhibits the growth of estrogen positive human breast cancer cells through modulation of estrogen receptor $\alpha$. Cancer Lett 300: 57-65, 2011.

24. Fribley AM, Miller JR, Brownell AL, Garshott DM, Zeng Q, Reist TE, Narula N, Cai P, Xi Y, Callaghan MU, et al: Celastrol induces unfolded protein response-dependent cell death in head and neck cancer. Exp Cell Res 330: 412-422, 2015.
25. Klaić L, Trippier PC, Mishra RK, Morimoto RI and Silverman RB: Remarkable stereospecific conjugate additions to the Hsp90 inhibitor celastrol. J Am Chem Soc 133: 19634-19637, 2011.

26. Hu L, Wu H, Li B, Song D, Yang G, Chen G, Xie B, Xu Z, Zhang Y, Yu D, et al: Dihydrocelastrol inhibits multiple myeloma cell proliferation and promotes apoptosis through ERK1/2 and IL-6/STAT3 pathways in vitro and in vivo. Acta Biochim Biophys Sin (Shanghai) 49: 420-427, 2017.

27. Ashton JC: Drug combination studies and their synergy quantification using the Chou-Talalay method - letter. Cancer Res 75: $2400,2015$.

28. Rudelius M, Rosenfeldt MT, Leich E, Rauert-Wunderlich H, Solimando AG, Beilhack A, Ott G and Rosenwald A: Inhibition of focal adhesion kinase overcomes resistance of mantle cell lymphoma to ibrutinib in the bone marrow microenvironment. Haematologica 103: 116-125, 2018

29. Zhou J, Tiemann K, Chomchan P, Alluin J, Swiderski P, Burnett J, Zhang X, Forman S, Chen R and Rossi J: Dual functional BAFF receptor aptamers inhibit ligand-induced proliferation and deliver siRNAs to NHL cells. Nucleic Acids Res 41: 4266-4283, 2013.

30. Sherr CJ and Roberts JM: CDK inhibitors: Positive and negative regulators of G1-phase progression. Genes Dev 13: 1501-1512, 1999.

31. Hassan M, Watari H, AbuAlmaaty A, Ohba Y and Sakuragi N: Apoptosis and molecular targeting therapy in cancer. BioMed Res Int 2014: 150845, 2014

32. Taylor RC, Cullen SP and Martin SJ: Apoptosis: Controlled demolition at the cellular level. Nat Rev Mol Cell Biol 9: 231-241, 2008.

33. Davids MS: Targeting BCL-2 in B-cell lymphomas. Blood 130: 1081-1088, 2017.

34. Dal Col J, Zancai P, Terrin L, Guidoboni M, Ponzoni M, Pavan A, Spina M, Bergamin S, Rizzo S, Tirelli U, et al: Distinct functional significance of Akt and mTOR constitutive activation in mantle cell lymphoma. Blood 111: 5142-5151, 2008.

35. Madrid LV, Mayo MW, Reuther JY and Baldwin AS Jr: Akt stimulates the transactivation potential of the RelA/p65 Subunit of NF-kappa B through utilization of the Ikappa B kinase and activation of the mitogen-activated protein kinase p38. J Biol Chem 276: 18934-18940, 2001.

36. Ahmad A, Biersack B, Li Y, Kong D, Bao B, Schobert R, Padhye SB and Sarkar FH: Targeted regulation of PI3K/Akt/ mTOR/NF- $\kappa$ B signaling by indole compounds and their derivatives: Mechanistic details and biological implications for cancer therapy. Anticancer Agents Med Chem 13: 1002-1013, 2013.

37. Tanaka K, Babic I, Nathanson D, Akhavan D, Guo D, Gini B, Dang J, Zhu S, Yang H, De Jesus J, et al: Oncogenic EGFR signaling activates an mTORC2-NF- $\mathrm{KB}$ pathway that promotes chemotherapy resistance. Cancer Discov 1: 524-538, 2011.

38. Lee K, Gudapati P, Dragovic S, Spencer C, Joyce S, Killeen N, Magnuson MA and Boothby M: Mammalian target of rapamycin protein complex 2 regulates differentiation of Th1 and Th2 cell subsets via distinct signaling pathways. Immunity 32: 743-753, 2010.

39. Stewart ZA, Westfall MD and Pietenpol JA: Cell-cycle dysregulation and anticancer therapy. Trends Pharmacol Sci 24: 139-145, 2003.

40. Halazonetis TD, Gorgoulis VG and Bartek J: An oncogeneinduced DNA damage model for cancer development. Science 319: 1352-1355, 2008 .

41. Riedl SJ and Salvesen GS: The apoptosome: Signalling platform of cell death. Nat Rev Mol Cell Biol 8: 405-413, 2007.

42. LoPiccolo J, Blumenthal GM, Bernstein WB and Dennis PA: Targeting the PI3K/Akt/mTOR pathway: Effective combinations and clinical considerations. Drug Resist Updat 11: 32-50, 2008

43. Sabatini DM: mTOR and cancer: Insights into a complex relationship. Nat Rev Cancer 6: 729-734, 2006.

44. Gingras AC, Gygi SP, Raught B, Polakiewicz RD, Abraham RT, Hoekstra MF, Aebersold R and Sonenberg N: Regulation of 4E-BP1 phosphorylation: A novel two-step mechanism. Genes Dev 13: 1422-1437, 1999.

45. Hsu PP, Kang SA, Rameseder J, Zhang Y, Ottina KA, Lim D, Peterson TR, Choi Y, Gray NS, Yaffe MB, et al: The mTOR-regulated phosphoproteome reveals a mechanism of mTORC1-mediated inhibition of growth factor signaling. Science 332: 1317-1322, 2011. 
46. Zhang HT, Wang WW, Ren LH, Zhao XX, Wang ZH, Zhuang DL and Bai YN: The mTORC2/Akt/NFKB pathway-mediated activation of TRPC6 participates in adriamycin-induced podocyte apoptosis. Cell Physiol Biochem 40: 1079-1093, 2016.

47. Lee K, Nam KT, Cho SH, Gudapati P, Hwang Y, Park DS Potter R, Chen J, Volanakis E and Boothby M: Vital roles of mTOR complex 2 in Notch-driven thymocyte differentiation and leukemia. J Exp Med 209: 713-728, 2012.

48. Bassères DS and Baldwin AS: Nuclear factor-kappaB and inhibitor of kappaB kinase pathways in oncogenic initiation and progression. Oncogene 25: 6817-6830, 2006.
49. Karin M: Nuclear factor-kappaB in cancer development and progression. Nature 441: 431-436, 2006.

50. Yun S, Vincelette ND, Knorr KL, Almada LL, Schneider PA, Peterson KL, Flatten KS, Dai H, Pratz KW, Hess AD, et al: 4EBP1/c-MYC/PUMA and NF- $\kappa$ B/EGR1/BIM pathways underlie cytotoxicity of mTOR dual inhibitors in malignant lymphoid cells. Blood 127: 2711-2722, 2016. 